\title{
Generation and Characterization of Specific Antibodies to the Murine and Human Ectonucleotidase NTPDase8
}

\author{
Julie Pelletier ${ }^{1}$, Mabrouka Salem ${ }^{1,2}$, Joanna Lecka ${ }^{1,2}$, Michel Fausther ${ }^{1,2,3}$, \\ François Bigonnesse ${ }^{1}$ and Jean Sévigny ${ }^{1,2 *}$
}

${ }^{1}$ Centre de recherche du CHU de Québec - Université Laval, Québec City, QC, Canada, ${ }^{2}$ Département de Microbiologie-Infectiologie et d'Immunologie, Faculté de Médecine, Université Laval, Québec City, QC, Canada, ${ }^{3}$ Division of Gastroenterology and Hepatology, Department of Internal Medicine, University of Arkansas for Medical Sciences, Little Rock, AR, USA

OPEN ACCESS

Edited by:

Kenneth A. Jacobson, National Institutes of Health, USA

Reviewed by:

Gennady G. Yegutkin, University of Turku, Finland Terence L. Kirley, University of Cincinnati, USA

*Correspondence: Jean Sévigny jean.sevigny@crchul.ulaval.ca

Specialty section: This article was submitted to Experimental Pharmacology and Drug

Discovery,

a section of the journal

Frontiers in Pharmacology

Received: 17 January 2017 Accepted: 24 February 2017

Published: 08 March 2017

Citation

Pelletier J, Salem M, Lecka J, Fausther M, Bigonnesse $F$ and

Sévigny J (2017) Generation and Characterization of Specific Antibodies to the Murine and Human

Ectonucleotidase NTPDase8.

Front. Pharmacol. 8:115. doi: 10.3389/fphar.2017.00115
The ectonucleotidase nucleoside triphosphate diphosphohydrolase-8 (NTPDase8) is the last member of the Ecto-NTPDase family to be discovered and characterized. It is a transmembrane protein which regulates the concentration of the agonists of $\mathrm{P} 1$ and P2 receptors at the cell surface. The functions of the enzyme are still not known partly due to the lack of specific tools such as antibodies. In this work, guinea pig polyclonal antibodies against mouse NTPDase8 and mouse monoclonal antibodies against human NTPDase8 have been generated and characterized. For the production of antibodies against mouse NTPDase8 several techniques have been tried. Several peptide antigens in several hosts (rabbit, rat, hamster, and guinea pig) failed to give a positive reaction suggesting that NTPDase8 is poorly immunogenic. In this study, we describe the successful process that led to anti-mouse NTPDase8, namely the cDNA immunization technique. Monoclonal antibodies to human NTPDase8 were also obtained by cDNA immunization followed by a final injection with transfected human embryonic kidney (HEK 293T) cells expressing human NTPDase8. The specificity of these antibodies was evaluated by Western blot, immunocytochemistry, immunohistochemistry and flow cytometry. In contrast, all commercial antibodies to NTPDase8 peptides that we have tested failed to give a specific positive signal against the expressed NTPDase8 protein when used to probe Western blots. In addition, immunohistochemistry experiments confirmed the presence of NTPDase8 in mouse liver canaliculi. The tools generated in this work will help characterize NTPDase8 localization and function in future studies and its contribution to the modulation of $\mathrm{P} 1$ and $\mathrm{P} 2$ receptor activation.

Keywords: monoclonal antibodies, polyclonal antibodies, mouse NTPDase8, human NTPDase8, cDNA immunization

\section{INTRODUCTION}

The activation of nucleotide (P2) and adenosine (P1) receptors is regulated in part by enzymes that regulate the concentration of their agonists at the cell surface. The most important enzymes that dephosphorylate nucleotides in the extracellular environment in physiological conditions are members of the Ecto-nucleoside triphosphate diphosphohydrolase (E-NTPDase) family (Beaudoin et al., 1996; Robson et al., 2006; Zimmermann et al., 2012). This family 
of ectonucleotidases is composed of 8 members (NTPDase1 to -8; Robson et al., 2006; Zimmermann et al., 2012). NTPDase1, -2, -3, and -8 are expressed at the plasma membrane and they hydrolyse nucleotides at the cell surface with different abilities (Kukulski et al., 2005). These enzymes have been located in different systems and they have been reported to play distinct roles. To give a few examples, NTPDase1, which is expressed by several cell types which includes vascular endothelial cells and Tregs, has been shown to regulate vascular hemostasis and immune functions (Kukulski et al., 2011; Zimmermann et al., 2012; Yegutkin, 2014). NTPDase2, which is also expressed by several cell types, is found in type I cells of taste buds where it has been associated to taste functions (Bartel et al., 2006; Vandenbeuch et al., 2013). NTPDase 3 has been detected in neurons in different organs. It was proposed that in the rat brain, NTPDase 3 may modulate feeding and sleep-wake behavior (Belcher et al., 2005). In contrast to NTPDase1, -2 , and -3 , no function has yet been associated to NTPDase8. Finally, as NTPDase4, $-5,-6$, and -7 are mainly anchored to the membranes of intracellular organelles and as they hydrolyse nucleotides with lower affinities their functions are expected to differ from the one of the above plasma membrane bound NTPDases.

So far NTPDase8 was reported to be expressed only in a few tissues which includes rat (Fausther et al., 2007) and porcine (Sévigny et al., 2000) liver, and pig kidneys (Sévigny et al., 2000). The lack of tools such as antibodies limits the study of NTPDase8 structure and function. To date, some commercial antibodies against NTPDase 8 are available, but their specificity has not been demonstrated. The goal of this work was to obtain specific antibodies against NTPDase 8 and to demonstrate their specificity. As the commercial antibodies revealed to be unspecific, to achieve this goal we used several techniques of immunization. Following several unsuccessful attempts we finally ended with a convenient technique that we also describe here.

\section{MATERIALS AND METHODS}

\section{Materials}

Aprotinin, phenylmethanesulfonyl fluoride, ethylenediaminetetraacetic acid, sodium citrate, paraformaldehyde (PFA), $3,3^{\prime}$-diaminobenzidine (DAB), and hydrogen peroxide $\left(\mathrm{H}_{2} \mathrm{O}_{2}\right)$ were purchased from Sigma-Aldrich (Oakville, ON, Canada). Tris(hydroxymethyl)aminomethane (Tris) was from VWR International (Montreal, QC, Canada). Dulbecco's modified Eagle's medium and antibiotic-antimycotic solution, NuPAGE lithium dodecyl sulfate sample, NuPAGE 4-12\% Bis-Tris gels were obtained from Life Technologies (Burlington, ON, Canada). Fetal bovine serum (FBS) and goat serum were from Wisent (St-Bruno, QC, Canada). For Western blot and/or immunohistochemistry experiments the secondary antibodies used were either conjugated to horseradish peroxidase (HRP), namely goat anti-guinea pig, donkey anti-goat (Santa Cruz Biotechnology, Dallas, TX, USA), goat anti-mouse (Jackson ImmunoResearch Laboratories Inc. West Grove, PA, USA), donkey anti-rabbit (GE Healthcare Life Sciences, Baie d'Urfe, QC, Canada), rabbit anti-rat (Thermo Fisher Scientific, Rockford,
IL, USA), or to biotin, namely goat anti-guinea pig, goat antirabbit (Jackson ImmunoResearch Laboratories Inc. West Grove, PA, USA), goat anti-mouse and goat anti-rat (Vector Laboratories, Burlington, ON, Canada). For flow cytometry experiments Alexa Fluor 594-goat anti-guinea pig and Alexa Fluor 633-goat anti-mouse were obtained from Life Technologies (Burlington, ON, Canada).

\section{Animals and Plasmids}

Female Sprague-Dawley rats, Hartley guinea pigs, LVG Golden Syrian hamsters, BALB/c mice, and New Zealand rabbits were obtained from Charles River Laboratories (Saint-Constant, QC, Canada). All procedures were approved by the Canadian Council on Animal Care and the Université Laval Animal Welfare Committee. The plasmids encoding mouse NTPDase1 (GenBank accession no. NM_009848; Enjyoji et al., 1999), mouse NTPDase2 (AY376711; Kukulski et al., 2005), mouse NTPDase3 (AY376710; Lavoie et al., 2004), mouse NTPDase8 (AY364442; Bigonnesse et al., 2004), human NTPDase1 (U87967; Kaczmarek et al., 1996), human NTPDase2 (NM_001246; Knowles and Chiang, 2003), a kind gift of Dr. A. F. Knowles (San Diego, CA, USA), human NTPDase3 (AF034840; Smith and Kirley, 1998), a kind gift of Dr. T. L. Kirley (Cincinnati, OH, USA), human NTPDase8 (AY430414; Fausther et al., 2007), or rat NTPDase8 (AY536920; Fausther et al., 2007) all in pcDNA 3.1 vector were used for antiserum generation and for/or cell transfection, as described below.

\section{Polyclonal Antibody Production to Mouse NTPDase8 with Peptides and Recombinant Proteins Produced in Bacteria}

High density multiple antigen peptides (MAPs) system generated using four lysine residues bearing four branching peptides were synthesized separately with two polypeptides: peptide 829 (MGLSWKERVFMALL) and peptide 830 (QWPANKEKDTGVVSQ) that correspond to amino acid 1-14 and 60-74, respectively. These two antigens were generated by the Proteomics Platform of the Centre de Recherche of the CHU de Québec. These peptides were injected at day 1, 43, $85,127,169,211$ in rabbits, at day 1, 29, 57, 92 in hamsters, and at day 1, 29, 57, 92, 146 in guinea pigs and rats. The amount of peptides injected was as follows: 400-650 $\mu \mathrm{g}$ for rabbits, $100-200 \mu \mathrm{g}$ for rats and guinea pigs, and $100 \mu \mathrm{g}$ for hamsters. The blood was collected prior to the first injection and 7 days post-injection. The peptides were diluted in phosphatebuffered solution (PBS) (in mM: $10.1 \mathrm{Na}_{2} \mathrm{HPO}_{4}, 1.8 \mathrm{KH}_{2} \mathrm{PO}_{4}$, $136.9 \mathrm{NaCl}$, and $2.7 \mathrm{KCl}, \mathrm{pH} 7.4$ ) and complete Freund's adjuvant was mixed at a ratio 1:1 with peptides for the first injection. Two other peptides conjugated to keyhole limpet hemocyanin (KLH) that correspond to amino acid 87-101 (SYTSDPTQAGESLKS) and 390-404 (VEVSYPGQERWLRDY) were also injected six times $(125-250 \mu \mathrm{g})$ in rabbit. The blood was collected 7 days post-injection. Recombinant purified protein produced in bacteria corresponding to amino acid 361-441 of mouse NTPDase8, named as peptide 76, was 
synthetized by the Molecular Biology and Production of Antibody Service of the Centre de Recherche du CHU de Québec. Rabbits were injected three times at day 1, 28, 56 and blood was collected 14 days after the second and the third injection.

\section{Polyclonal Antibodies by cDNA Immunization}

Genetic immunization was carried out with plasmids encoding mouse NTPDase8 diluted in PBS $0.8 \times$. Rabbits were injected with $1 \mathrm{~mL}$ of mouse NTPDase $8 \mathrm{cDNA}(0.65-0.8 \mathrm{mg} / \mathrm{mL})$ consisting of 10 intradermic (ID) sites of $50 \mu \mathrm{L}$ each and two intramuscular (IM) sites of $250 \mu \mathrm{L}$ each. Hamsters were injected with $0.1 \mathrm{~mL}$ of mouse NTPDase 8 cDNA $(1 \mathrm{mg} / \mathrm{mL})$ consisting of two ID sites of $25 \mu \mathrm{L}$ each and one IM site of $50 \mu \mathrm{L}$. Guinea pigs and rats were injected with $0.2 \mathrm{~mL}$ of mouse NTPDase $8 \mathrm{cDNA}(1 \mathrm{mg} / \mathrm{mL})$ consisting of two ID sites of $50 \mu \mathrm{L}$ each and one IM site of $100 \mu \mathrm{L}$. Rabbits and hamsters were injected at day 1, 15, 29, 99, 183, 253, $286,316,384$, and at day $1,15,29,99,170$, respectively, rats and guinea pigs were injected at day $1,15,29,99,170,283$. The intradermal injections were done in the dorsal skin and the IM injections were done in the hind leg. The blood was collected prior to the first injection and between 12 and 14 days after the third and the subsequent injection.

\section{Monoclonal Antibody Production by cDNA Immunization}

Hybridomas were generated in $\mathrm{BALB} / \mathrm{c}$ mice by ID and IM injection with $100 \mu \mathrm{g}$ of human NTPDase $8 \mathrm{cDNA}$ diluted in PBS $0.8 \times$ at day $1,15,29,99$, and 184 . A final injection was made at day 297 using intact human embryonic kidney (HEK 293T) cells transfected with human NTPDase8 expression vector (see Cell Transfection and Western Blot). Spleen cells were collected 3 days after the prime boost cells injection and fusion with SP2/0 cells were done as previously described (Munkonda et al., 2009) with minor modifications. For this assay, the SP $2 / 0$ cells were combined with splenocytes at a ratio 1:5. The positive hybridomas were screened by enzyme-linked immunosorbent assay (ELISA). The hybridomas were cloned by limiting dilution and the produced immunoglobulins were purified on Protein A Sepharose CL-4B column as described (Munkonda et al., 2009).

\section{ELISA and Isotyping for Monoclonal Antibodies}

ELISA plates (96 wells) were coated overnight $(\mathrm{O} / \mathrm{N})$ with $500 \mathrm{ng}$ per well of lysates from African green monkey kidney (COS-7) cells transiently transfected with human NTPDase8 or untransfected diluted in PBS. After washing with PBSTween $0.05 \%$ (PBS-T), the wells were incubated for $1 \mathrm{~h}$ at $37^{\circ} \mathrm{C}$ in a blocking solution $(0.5 \%$ bovine serum albumin diluted in PBS-T). After washing, the supernatant from each hybridoma was added to the well and incubated for $2 \mathrm{~h}$ at room temperature (RT), followed by four washing steps. Then a goat anti-mouse $\operatorname{IgG}(\mathrm{H}+\mathrm{L})$-HRP (1:2500) diluted in the blocking solution was incubated for $2 \mathrm{~h}$ at RT followed by four washing steps. The Enhanced K-Blue ${ }^{\circledR}$ Substrate (Neogen
Corporation, Lansing, MI, USA) was then added for $15 \mathrm{~min}$ and the reaction was stopped by the addition of an equal volume of $2 \mathrm{~N}$ sulphuric acid and absorbance at $450 \mathrm{~nm}$ was recorded. The isotype of the antibodies produced by each hybridoma was determined by a Mouse Immunoglobulin Isotyping ELISA Kit (BD Bioscience, Mississauga, ON, Canada) according to the manufacturer's instruction. In brief, monoclonal rat antimouse IgG1, IgG2a, IgG2b, IgG3, IgA, and IgM were coated $\mathrm{O} / \mathrm{N}$ in 96-well plates. After a washing step and a blocking treatment, each monoclonal anti-human NTPDase8 antibody was transferred to the wells. After washing steps, a rat antimouse Ig conjugated to HRP was added to each well, and revealed with a substrate provided in the kit. The plate was then read at $450 \mathrm{~nm}$.

\section{Cell Transfection and Western Blot}

COS-7 cells and HEK 293T cells were cultured and transiently transfected as indicated with mouse NTPDase8 or human NTPDase8 cDNA constructs as described previously (Kukulski et al., 2005). For Western blot assays, lysates from transfected or non-transfected COS-7 cells (6 $\mu \mathrm{g}$, unless otherwise indicated) were resuspended in NuPAGE sample buffer, separated on NuPAGE $4-12 \%$ Bis-Tris gels under reduced or non-reduced conditions, as indicated, and transferred to an Immobilon-P membrane (Millipore, Bedford, MA, USA) by electroblotting according to the manufacturer's recommendation. Membranes were then blocked with $2.5 \%$ non-fat milk in PBS containing $0.15 \%$ Tween $20^{\circledR}(\mathrm{pH} 7.4) \mathrm{O} / \mathrm{N}$ at $4^{\circ} \mathrm{C}$ and subsequently probed with the primary antibodies. Appropriate secondary HRPconjugated antibodies were used, and the membranes developed with the Western Lightning ${ }^{\mathrm{TM}}$ Plus-ECL system (PerkinElmer Life and Analytical Sciences, Waltham, MA, USA). In some experiments, a gel with a large sample well $6 \mathrm{~cm}$ long containing $120 \mu \mathrm{g}$ of lysates, transferred and blocked as described above and then probed with antibodies using the Mini-Protean II multiscreen apparatus (Bio-Rad Laboratories Ltd., Mississauga, ON, Canada) in which 20 antibodies can be tested on one gel.

\section{Immunocytochemistry and Immunohistochemistry}

Mouse liver was collected after animal perfusion with 4\% PFA, tissues were then fixed in 4\% PFA for $2 \mathrm{~h}$ and incubated $\mathrm{O} / \mathrm{N}$ in $4 \%$ sucrose at $4^{\circ} \mathrm{C}$ and frozen in Tissue-Tek ${ }^{\circledR}$ O.C.T. ${ }^{\text {TM }}$ Compound (Sakura Finetek, Torrance, CA, USA). COS-7 cells or tissues sections (6 $\mu \mathrm{m}$ thick) of mouse liver were fixed in $10 \%$ phosphate-buffered formalin (Fisher Scientific, Ottawa, ON, Canada) mixed with cold acetone (Fisher Scientific, Ottawa, ON, Canada) and blocked in a PBS solution containing $7 \%$ normal goat serum for $30 \mathrm{~min}$. COS-7 cells and tissue sections were incubated with the indicated primary antibody at $4^{\circ} \mathrm{C}$. COS-7 cells and tissue sections were then treated with $0.15 \% \mathrm{H}_{2} \mathrm{O}_{2}$ in $\mathrm{PBS}$ for $10 \mathrm{~min}$ to inactivate endogenous peroxidase, and with an avidin/biotin solution (Avidin/Biotin Blocking kit; Vector Laboratories, Burlington, ON, Canada) to prevent non-specific staining due to endogenous biotin. 
This step was followed by incubation with an appropriate biotin-conjugated secondary antibody at a dilution of 1:1000. The avidin-biotinylated HRP complex (VectaStain Elite ABC kit; Vector Laboratories) was added to optimize the reaction. Peroxidase activity was revealed with $\mathrm{DAB}$ as the substrate. Nuclei were counterstained with aqueous hematoxylin (Biomeda, Foster City, CA, USA) in accordance with the manufacturer's instructions.

\section{Flow Cytometry (FACS)}

HEK 293T cells transfected with mouse or human NTPDase8, were detached from the plates with a citric saline solution (135 mM potassium chloride, $15 \mathrm{mM}$ sodium citrate). Samples of $2.5 \times 10^{5}$ cells per tube were washed with an ice-cold PBS solution containing $1 \% \mathrm{FBS}$ and $0.1 \% \mathrm{NaN}_{3}$ [fluorescenceactivated cell sorting (FACS) buffer] followed by incubation with the primary antibodies (serum from polyclonal antimouse NTPDase8 or purified monoclonal antibodies to human NTPDase8) or negative control (guinea pig preimmune sera or control mouse IgG2a (Sigma-Aldrich, Oakville, ON, Canada)) in
FACS buffer for $1 \mathrm{~h}$. After washes with FACS buffer solution, the cells were incubated with an appropriate Alexa-conjugated secondary antibody for 30 min on ice, washed with FACS buffer, and analyzed by flow cytometry (BD LSR II, BD Biosciences, San Jose, CA USA).

\section{Inhibition Assays}

Inhibition assay were done as previously described (Munkonda et al., 2009) on cell lysates from human NTPDase8 transfected COS-7 cells at $37^{\circ} \mathrm{C}$ in two different buffers: modified Ringer buffer $\left(120 \mathrm{mM} \mathrm{NaCl}, 5 \mathrm{mM} \mathrm{KCl}, 2.5 \mathrm{mM} \mathrm{CaCl}_{2}, 1.2 \mathrm{mM}\right.$ $\mathrm{MgSO}_{4}, 25 \mathrm{mM} \mathrm{NaHCO} 3,5 \mathrm{mM}$ dextrose, $80 \mathrm{mM}$ Tris- $\mathrm{HCl}$, $\mathrm{pH}$ 7.4) and Tris/calcium buffer ( $5 \mathrm{mM} \mathrm{CaCl}_{2}, 80 \mathrm{mM}$ Tris$\mathrm{HCl}, \mathrm{pH}$ 7.4). After pre-incubation of the enzyme with the purified monoclonal antibodies to human NTPDase8 $(5 \mu \mathrm{g} / \mathrm{mL})$, substrate (ATP, $100 \mu \mathrm{M}$ ) was then added and incubated for 8$10 \mathrm{~min}$, the reaction was then stopped with malachite green reagent. The inorganic phosphate released during the enzymatic reaction was measured as previously described with the malachite green assay (Baykov et al., 1988).

TABLE 1 | Antigen used and specificity of the antibodies to mouse and human NTPDase8.

\begin{tabular}{|c|c|c|c|c|c|c|c|c|}
\hline \multirow[t]{3}{*}{ Antigen } & \multirow[t]{3}{*}{ Conjugation } & \multirow[t]{3}{*}{ Host } & \multirow{3}{*}{$\begin{array}{l}\text { Animals per } \\
\text { group }\end{array}$} & \multicolumn{5}{|c|}{ Application } \\
\hline & & & & \multicolumn{2}{|c|}{ WB } & \multirow[t]{2}{*}{ IHC } & \multirow[t]{2}{*}{ ICC } & \multirow[t]{2}{*}{ FACS } \\
\hline & & & & NR & Red. & & & \\
\hline \multicolumn{9}{|c|}{ Antibodies to mouse NTPDase8 (accession number: AY364442) } \\
\hline \multirow[t]{5}{*}{ Expression vector encoding mouse NTPDase8 } & None & Rabbit & 3 & - & - & - & NT & NT \\
\hline & & Rat & 6 & - & NT & - & $+(2 / 6)$ & NT \\
\hline & & Hamster & 6 & - & NT & - & - & NT \\
\hline & & Guinea pig & 6 & $+(5 / 6)$ & NT & - & $+(5 / 6)$ & NT \\
\hline & & Guinea pig & 5 & ++ & - & ++ & ++ & ++ \\
\hline \multirow[t]{4}{*}{ Peptide 829 (aa 1-14): MGLSWKERVFMALL } & MAPs & Rabbit & 2 & - & - & - & NT & NT \\
\hline & & Rat & 3 & NT & - & NT & NT & NT \\
\hline & & Hamster & 3 & NT & - & NT & NT & NT \\
\hline & & Guinea pig & 3 & NT & - & NT & NT & NT \\
\hline \multirow[t]{4}{*}{ Peptide 830 (aa 60-74): QWPANKEKDTGWSQ } & MAPs & Rabbit & 2 & - & - & - & NT & NT \\
\hline & & Rat & 3 & NT & - & NT & NT & NT \\
\hline & & Hamster & 3 & NT & - & NT & NT & NT \\
\hline & & Guinea pig & 3 & NT & - & NT & NT & NT \\
\hline Peptide 6768 (aa 87-101): SYTSDPTQAGESLKS & $\mathrm{KLH}$ & Rabbit & 2 & NT & + & NT & NT & NT \\
\hline Peptide 6970 (aa 390-404): VEVSYPGQERWLRDY & $\mathrm{KLH}$ & Rabbit & 2 & NT & - & NT & NT & NT \\
\hline Peptide 76 (aa 361-441) & None & Rabbit & 3 & NT & - & NT & NT & NT \\
\hline Santa Cruz Biotechnologies (sc-160611) ${ }^{1}$ & Unknown & Goat & N/A & NT & - & NT & NT & NT \\
\hline \multicolumn{9}{|c|}{ Antibodies to human NTPDase8 (accession number: AY430414) } \\
\hline Expression vector encoding human NTPDase8 & None & Mouse & $9^{2}(4 \mathrm{mAbs})$ & ++ & ++ & ++ & NT & + \\
\hline Aviva Systems Biology (ARP44815_P050) & Unknown & Rabbit & N/A & NT & - & NT & NT & NT \\
\hline
\end{tabular}

Peptide aa 110-159

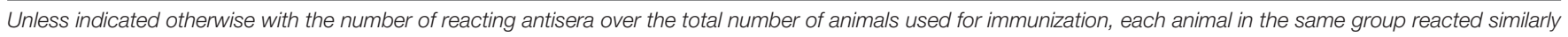
in the experiments presented.

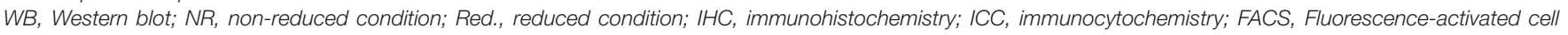

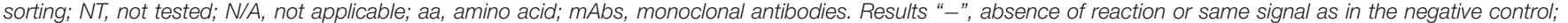

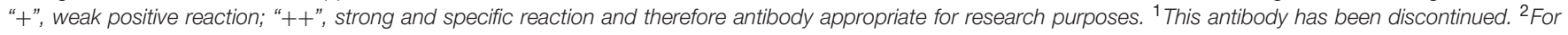

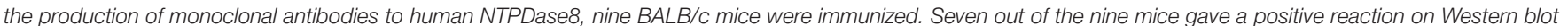

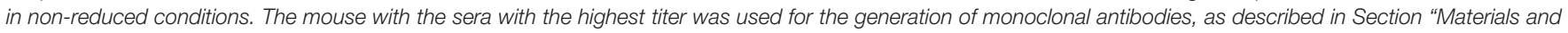
Methods." The four monoclonal antibodies obtained gave similar results for all experiments as indicated in the table. 

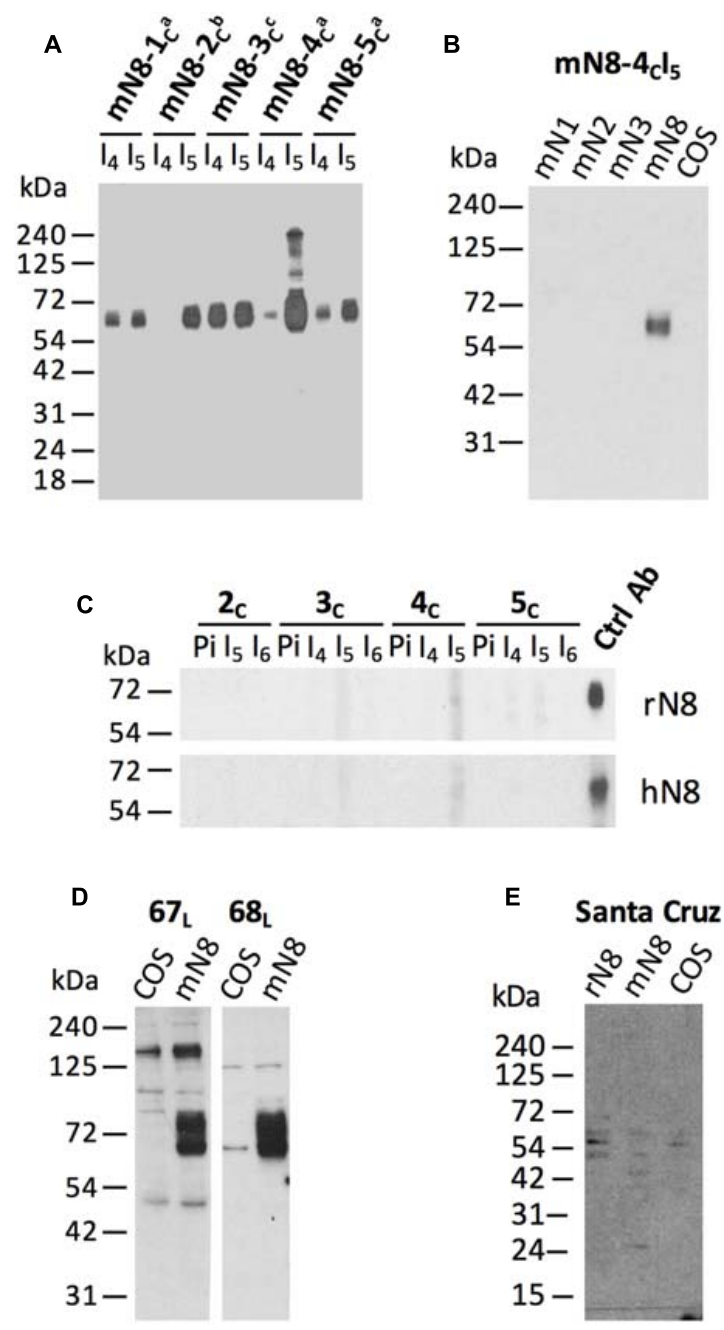

FIGURE 1 | Specificity of the polyclonal antibodies to mouse NTPDase 8 by Western blot. (A) Lysates $(120 \mu \mathrm{g})$ for one large well from COS-7 cells transfected with mouse NTPDase8, were subjected to electrophoresis and probed with the five guinea pig $\left(\mathrm{mN8}-1_{c} ;-2_{c} ;-3_{C} ;-4_{c} ;-5_{C}\right)$ antisera [bleeding after the fourth $\left(I_{4}\right)$ and fifth $\left(I_{5}\right)$ injection] against mouse NTPDase8 at different dilution (a: 1:1000; b: 1:500; c: 1:2000). (B) NTPDases specificity tested on lysates from COS-7 cells transfected with mouse NTPDase1 (mN1), -2 (mN2), -3 (mN3), -8 (mN8) or from non-transfected COS-7 cells (COS) and probed with the guinea pig anti-mouse NTPDase8 $\mathrm{mN} 8-4_{C} \mathrm{I}_{5}$ at a dilution of 1:1000. (C) Species specificity tested on lysates (120 $\mu \mathrm{g}$; large well) of COS-7 cells transfected with either rat (rN8) or human (hN8) NTPDase8 and incubated with four guinea pig antisera corresponding to the bleedings after the fourth $\left(I_{4}\right)$, the fifth $\left(I_{5}\right)$ and the sixth $\left(I_{6}\right)$ injection or with the preimmune serum at a dilution of 1:500. Control antibodies to rat NTPDase8, rN8-8 $I_{5}(1: 1000)$ (previously described by Fausther et al., 2007) and to human NTPDase8, hN8-C5s $(0.2 \mu \mathrm{g} / \mathrm{mL})$ were used to confirm the presence of rat or human NTPDase8 protein in COS-7 lysates. (D) Lysates from COS-7 cells transfected with mouse NTPDase8 expression vector (mN8) or non-transfected (COS) and incubated with either mN8-67 $\mathrm{I}_{5}$ or mN8-68 $\mathrm{L}_{6}$ antiserum diluted 1:500 from rabbits immunized with peptide 6768 conjugated to $\mathrm{KLH}$. (E) Lysate from COS-7 cells transfected with mouse $(\mathrm{mN} 8)$ or rat (rN8) NTPDase8 or non-transfected (COS) and incubated with a commercial anti-mouse NTPDase8 (1:200) from Santa Cruz Biotechnology Inc. (Dallas, TX, USA). All gels were run under non-reduced conditions except in panel (D) and $(\mathbf{E})$ where the protein samples were treated with $\beta$-mercaptoethanol.

\section{RESULTS}

For many years we struggled to produce antibodies to mouse NTPDase8. We will present below our unsuccessful attempts that may help other groups to avoid these problems and improve their chances of success. We also present an efficient and convenient technique that we used to obtain excellent antibodies to several ectonucleotidases that are now available at ectonucleotidasesab.com. In addition, we have tested the antibodies produced by different companies against mouse and human NTPDase8.

\section{Antibodies to Mouse NTPDase8}

For the generation of mouse NTPDase8 antibodies, we first produced short peptides conjugated to KLH or in the form of MAPs. The number of animals tested for each antigen and conjugation type is indicated in Table 1. The MAPs was synthesized with peptide 829 and 830 corresponding to amino acid 1-14 and 60-74, respectively. These conjugated peptides and MAPs were injected in rabbits, hamsters, guinea pigs, and rats. The antiserum obtained for each animal was tested by Western blot under reduced condition. Note that all antisera generated from the immunization of peptides as an antigen were tested only by Western blot under denaturing conditions as this is the most likely technique that should work with such antigens. Generally, when no specific signal was obtained by Western blot with the sera from an animal immunized with peptides, no further experiments were done. The situation with intact and native proteins is different and will be described below. From all the sera with animals immunized with these MAPs, none of them gave a specific signal for mouse NTPDase8 (Table 1 and data not shown).

Two other peptides conjugated to $\mathrm{KLH}$, were injected in rabbits. The antisera from the rabbits injected with the peptide corresponding to amino acid 87-101 of mouse NTPDase8 showed a signal on lysate of mouse NTPDase8 transfected cells in Western blot (Figure 1D). Due to high level background, these antibodies were not further used in other techniques. No specific signal was obtained with the sera of rabbits injected with the KLH conjugated peptide corresponding to amino acid 390-404 (data not shown).

The service of Molecular Biology and Production of Antibody Service of the Centre de Recherche du CHU de Québec produced in bacteria a mouse NTPDase8 recombinant section from amino acid 361 to 441 (peptide 76). The peptide was purified by affinity chromatography on nickel-nitrilotriacetic acid resin, dialyzed and injected in rabbits. Again, none of the antisera obtained detected mouse NTPDase 8 by Western blot in reduced condition (data not shown). Note that the peptides tested above were selected following in silico analysis using different programs to determine the hydrophobicity, antigenicity and sequence homology such as Peptool (BioTools Incorporated, Edmonton, $\mathrm{AB}$, Canada) and Kyte and Doolittle hydrophobicity scale. The $\mathrm{N}$-terminal region generally known to represent a good choice for immunization was also synthetized. Unfortunately, little success was obtained with these peptides as detailed above.

Injections of mouse NTPDase8 cDNA were then used in rabbits, hamsters, rats, and guinea pigs. The serum obtained for 

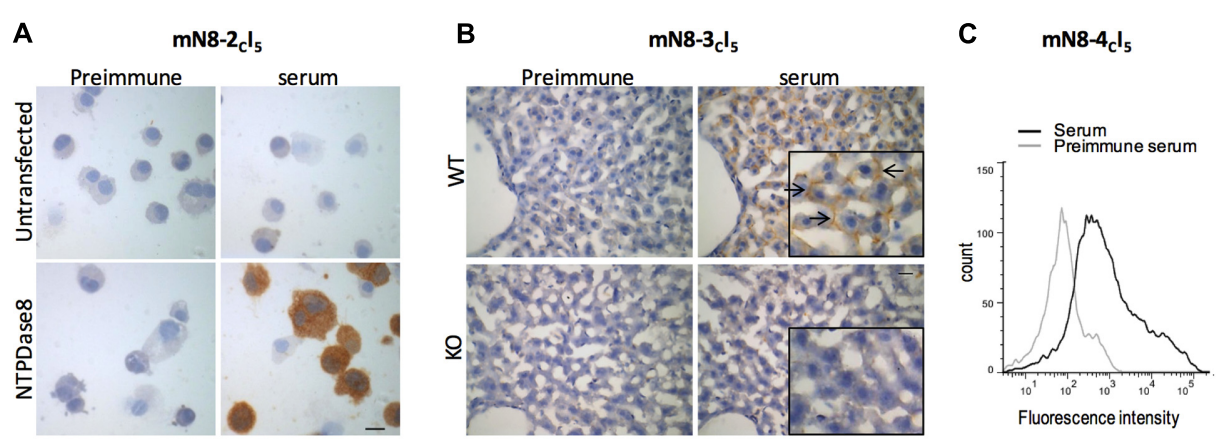

FIGURE 2 | Specificity of the best antisera for immunocytochemistry, immunohistochemistry, and flow cytometry. (A) Immunocytochemistry of COS-7 cells transfected with mouse NTPDase8 (lower panels) or non-transfected COS-7 cells (upper panels) were probed with the guinea pig anti-mouse NTPDase8 $\mathrm{mN8}-2_{C} I_{5}$ (right panels), or with its preimmune serum (left panels), both at a 1:250 dilution. (B) Immunohistochemistry on a liver deficient in NTPDase8 expression (lower panels) or on a wild type (WT) mouse liver (upper panels) incubated with the preimmune serum (left panels) or the antiserum $\mathrm{mN} 8-3_{\mathrm{c}} \mathrm{I}_{5}$ (right panels) at a dilution of 1:500. Insets are $2 \times$ magnifications. Arrows show stained canaliculi. (C) Flow cytometry on mouse NTPDase8 transfected HEK 293 T cells incubated with the $\mathrm{mN} 8-4_{c} I_{5}$ antiserum or its preimmune serum both at 1:80 dilution. In panels (A) and (B), counterstaining of nuclei (blue) was performed with aqueous hematoxylin. Scale bar $25 \mu \mathrm{m}$.
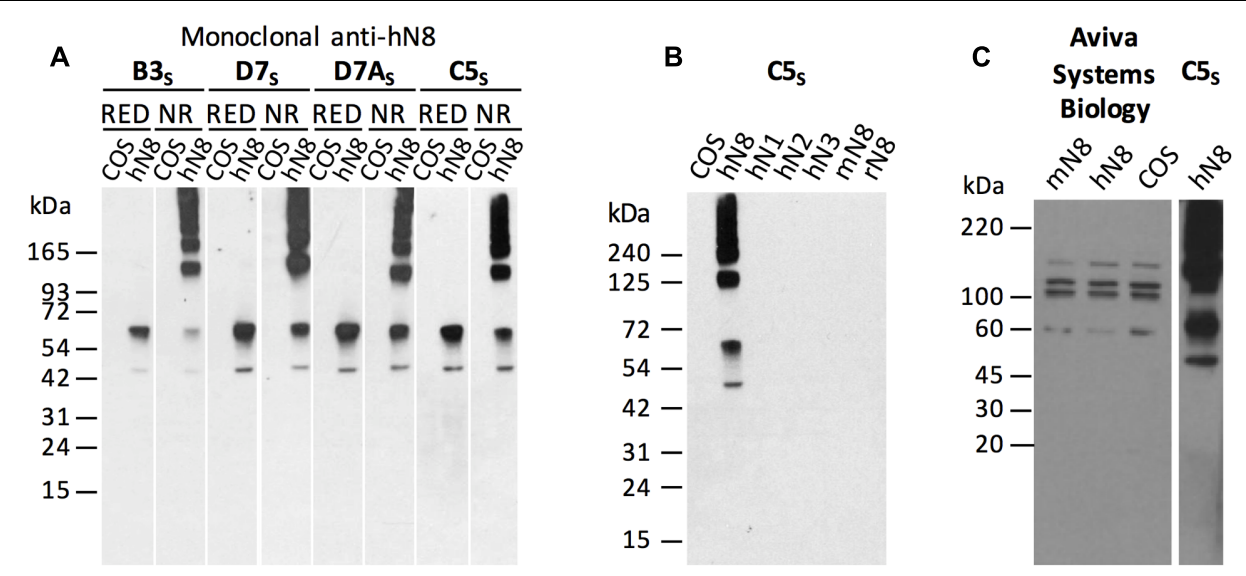

FIGURE 3 | Specificity of the mouse monoclonal antibodies to human NTPDase8 by Western blot. (A) Western blotting using lysates from COS-7 cells transfected with human NTPDase8 (hN8) or non-transfected cells (COS) in reduced (RED) or in non-reducing conditions (NR) were incubated separately with each anti-human NTPDase8 hybridoma, hN8-B3 ${ }_{s},-D 7_{s},-D 7 A_{s}$, and $-\mathrm{C}_{s}$, as indicated. (B) Specificity of hN8-C5s $(0.5 \mu \mathrm{g} / \mathrm{mL})$ antibody on lysates from COS-7 transfected with human NTPDase1 (hN1), -2 (hN2), -3 (hN3), -8 (hN8), mouse NTPDase8 (mN8), rat NTPDase8 (rN8) or non-transfected cells (COS) in non-reduced condition. (C) A commercial anti-human NTPDase8 antibody from Aviva Systems Biology tested on lysates from COS-7 transfected with mouse (mN8) or human (hN8) NTPDase8 as well as non-transfected cells (COS) in reduced condition (left panel). A positive control in non-reduced conditions on a human NTPDase8 COS-7 cell lysate probed with $\mathrm{hN8}-\mathrm{C} 5_{\mathrm{s}}$ antibody was performed on the same gel. Additional note. Panels (A) and (B) represent two gels performed in the same time. The first 12 lanes of panel (A) constitute the first gel and the last four lanes were part of the gel presented in panel (B). The last two lanes of panel (A) (COS and hN8) are reproduced in the first two lanes of panel (B). Each demarcation shown in panels (A) and (C) represents a lane with non-reduced COS lysates used to stop diffusion of $\beta$-mercaptoethanol. These lanes were cut out of the data presented.

each animal was tested by Western blot. As the antigen here is the complete native form of mouse NTPDase 8 produced by the host cells, the Western blots were first carried out in nonreducing conditions. No specific staining was obtained either with the rabbits, the hamsters or the rats (data not shown). On the other hand, the antisera developed by guinea pigs gave a weak signal on lysate from mouse NTPDase8 transfected COS-7 cells (data not shown). Of all the techniques used and from all species tested, the guinea pigs injected with cDNA was the technique and the species from which the best results were obtained. As the antisera of the first group of guinea pigs were positive but not sufficiently strong to work with, we repeated with a second series of five guinea pigs with the cDNA immunization technique. The sera of those last 5 guinea pigs gave a strong positive signal in Western blot with different intensity levels at the right molecular weight (Figure 1A). The detected band in Western blot for mouse NTPDase8 appears higher than the calculated molecular weight $(54,650 \mathrm{Da})$ due to eight potential $\mathrm{N}$-linked glycosylation sites. We do not have an explanation for the difference in immunoreactivity between the first groups of guinea pigs and the second group. 


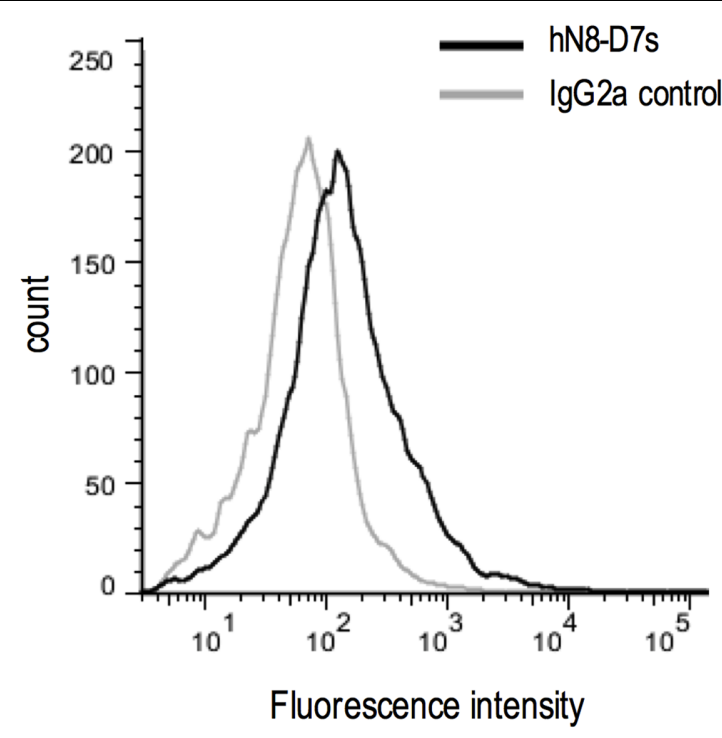

FIGURE 4 | Specificity of hN8-D7s by flow cytometry. Flow cytometry on human NTPDase8 transfected HEK 293T cells and incubated with an anti-human NTPDase8 (hN8-D7s) or its isotype control both used at $10 \mu \mathrm{g} / \mathrm{mL}$.

The cross-reactivity of the two best antibodies $\left(\mathrm{mN} 8-3_{c} \mathrm{I}_{5}\right.$ and $\mathrm{mN} 8-4_{c} \mathrm{I}_{5}$ ) was tested on lysates of COS-7 cells transfected with other closely related members of the mouse E-NTPDase family as well as with non-transfected cells. Figure 1B shows that the antiserum $\mathrm{mN} 8-4_{c} \mathrm{I}_{5}$ does not recognize mouse NTPDase1, $2,-3$ or any other proteins from non-transfected COS-7 cells. Similar results were obtained for the other antibody tested: mN8$3_{c} \mathrm{I}_{5}$ (data not shown). The specificity was also confirmed on recombinant NTPDase8 from rat and human species, as shown on Figure 1C, no antiserum after the fourth $\left(\mathrm{I}_{4}\right)$, the fifth $\left(\mathrm{I}_{5}\right)$ and the sixth injection $\left(\mathrm{I}_{6}\right)$ of those guinea pigs $\left(\mathrm{mN8}-2_{c} ;-3_{c}\right.$; $\left.4_{c} ;-5_{c}\right)$ cross-reacted with these two species. Similar results were obtained with $\mathrm{mN} 8-1_{c}$ on rat NTPDase8 (data not shown). These four guinea pig antisera $\left(\mathrm{mN} 8-2_{c} ;-3_{c} ;-4_{c} ;-5_{c}\right)$ were also tested in reduced conditions against mouse NTPDase 8 but none of them recognized the protein reduced with $\beta$-mercaptoethanol (data not shown).

We next tested whether the best antisera on Western blot could immunolocalize NTPDase 8 by immunocytochemistry and immunohistochemistry. The antisera $\mathrm{mN} 8-2_{c} \mathrm{I}_{5}$ gave a strong positive signal on cells transfected with an expression vector encoding mouse NTPDase8 (Figure 2A, lower right panel). The absence of staining in non-transfected COS-7 cells confirmed the specificity of the reaction (Figure 2A, upper right panel). In addition, no signal could be detected with the preimmune serum either on non-transfected or NTPDase8 transfected COS-7 cells (Figure 2A, left panels). Similar results were obtained with the $\mathrm{mN} 8-3_{c} \mathrm{I}_{6}$ and $\mathrm{mN} 8-4_{c} \mathrm{I}_{5}$ antiserum (data not shown).

These antisera were also efficient and specific to detect the native NTPDase 8 by immunohistochemistry, as evaluated by use of wild type and knockout mouse for Entpd8 gene. We previously demonstrated the presence of NTPDase 8 in rat (Fausther et al., 2007) and porcine liver canaliculi (Sévigny et al., 2000). We have also detected the presence of mRNA in mouse liver (Bigonnesse et al., 2004) suggesting that this protein may also be found in the same structure in mouse. As expected, $\mathrm{mN} 8-3_{c} \mathrm{I}_{5}$ antiserum stained the canaliculi in the wild type mouse liver but not in the NTPDase 8 knockout mouse (Figure 2B). Similar results were obtained with $\mathrm{mN} 8-1_{c} \mathrm{I}_{5} ;-2_{c} \mathrm{I}_{5} ;-4_{\mathcal{c}} \mathrm{I}_{5} ;-5_{c} \mathrm{I}_{5}$ antiserum (data not shown).

Each of the last five guinea pig anti-mouse NTPDase8 antisera was also efficient in flow cytometry. Indeed, they showed a shift in fluorescence intensity on cells transfected with a mouse NTPDase8 expression vector when compared with the preimmune serum (Figure $2 \mathrm{C}$ for $\mathrm{mN} 8-4_{c} \mathrm{I}_{5}$ and data not shown for the other guinea pig antisera). Overall, these data indicate that the guinea pig antibodies detect the native mouse NTPDase8 protein.

In contrast to the immunization techniques that use native proteins as a source of antigen, as in the cDNA immunization technique with the full gene encoded as we did here, the commercial anti-mouse NTPDase8 from Santa Cruz Biotechnology Inc. was generated against a synthetic polypeptide. Therefore, if it can detect mouse NTPDase8 it must do in Western blot in denaturing and reduced conditions. In these conditions, the same non-specific bands were detected in both, lysates from transfected cells with mouse NTPDase 8 and from non-transfected cells (Figure 1E).

\section{Antibodies to Human NTPDase8}

Hybridomas were generated from B-cells of BALB/c mice injected with human NTPDase 8 cDNA. As our previous assays using only cDNA immunization were ineffective for some proteins (data not shown), we have made the final boost with intact HEK 293T cells transfected with the same human NTPDase8 expression vector to increase the titer and our chances of success in obtaining hybridomas. Even if the background would be expected to increase in the sera, this is not an issue with monoclonal antibodies. With this technique, we obtained four hybridomas by limiting dilution named $\mathrm{hN} 8-\mathrm{B} 3_{\mathrm{s}}, \mathrm{hN} 8-\mathrm{C} 5_{\mathrm{s}}$, hN8-D7s, and hN8-D7As, which produced a positive response in ELISA on lysates of human NTPDase8 transfected cells, and a negative signal with lysates from non-transfected cells. The specificity of these monoclonal antibodies was tested by Western blot, ELISA, and flow cytometry.

The four hybridomas were tested in Western blot on lysates from COS-7 cells transfected with human NTPDase8 or nontransfected cells in reduced and non-reduced condition. As demonstrated in Figure $\mathbf{3 A}$, human NTPDase8 antibodies recognize human NTPDase8 proteins in both reduced and non-reduced forms, suggesting that the higher bands observed over $65 \mathrm{kDa}$ in the non-reduced samples are due to multimer formation. Indeed, none of these higher molecular weight bands are detected in the control sample proteins. Human NTPDase8 have a calculated molecular weight of 53,773 $\mathrm{Da}$ plus seven potential glycosylation sites for about $2-4 \mathrm{kDa}$ each. In addition, the specificity of these four hybridomas was also tested in Western blot on other human NTPDases (NTPDase1, -2, -3) and 
on other NTPDase8 species (mouse and rat) using lysates from transfected COS-7 transfected as well as from non-transfected cells. As illustrated in Figure 3B, the antibody named hN8$\mathrm{C}_{5}$ detected only human NTPDase8. No cross-reaction was observed with human NTPDase1, $-2,-3$ nor with the mouse or rat NTPDase8 showing that these antibodies are highly specific. Similar results were obtained for the three other antibodies.

The isotype of the antibodies produced by these hybridomas were determined by ELISA using rat monoclonal antibodies specific for different mouse immunoglobulin which revealed that all four hybridomas are IgG2a (data not shown).

The four purified hybridomas anti-human NTPDase8 were tested by flow cytometry on human NTPDase8 transfected HEK 293T cells. All hybridomas produced a shift in the fluorescence at different intensity; the best antibody for this technique was hN8-D7s (diluted at $10 \mu \mathrm{g} / \mathrm{mL}$; Figure 4), data not shown for the three other monoclonal antibodies.

These four monoclonal antibodies were also tested in enzyme activity inhibition assays but none of them were able to inhibit human NTPDase8 (data not shown).

The commercial anti-human NTPDase8 (Aviva Systems Biology, San Diego, CA, USA) was tested by Western blot. No specific staining at the expected molecular weight could be detected in reduced conditions. As seen in Figure 3C, the bands obtained were the same in the positive samples [COS-7 cells transfected with human NTPDase8 (hN8)] and in the negative control [non-transfected COS-7 cells $(\mathrm{COS})]$.

\section{DISCUSSION}

In the present work, we have generated polyclonal antibodies against mouse NTPDase8 and four hybridomas that produce IgG2a against human NTPDase8. Many experimental approaches were necessary to generate antibodies against mouse NTPDase8, indeed, even if five different peptides were used to produce antibodies against mouse NTPDase8 injected in different hosts, and conjugated differently, only the peptides corresponding to amino acid 87-101 conjugated to KLH injected in rabbits gave a positive band on Western blot. The immunization with an expression vector encoding for the full coding sequence of mouse NTPDase8 in rabbit, guinea pig, rat, and hamster gave successful result only in guinea pigs (Table 1). This technique was also useful for the production of antibodies against several other ectonucleotidases (Sévigny et al., 2002; Bartel et al., 2006; Vekaria et al., 2006; Fausther et al., 2007, 2012; Martín-Satué et al., 2009). The guinea pig anti-mouse NTPDase8 antibodies were validated in different techniques. They are specific and efficient for immunohistochemistry, for immunocytochemistry, for flow cytometry as well as for Western blot but only in non-reduced conditions, suggesting that the epitope is discontinuous and part of a tertiary structure of the protein involving disulphide bridges. These antibodies were very specific to mouse NTPDase8 and they did not cross-react with cells transfected with the other NTPDases that show the highest homology to NTPDase8, between 39 and $44 \%$ identity, namely NTPDase1, -2 , and -3 (Bigonnesse et al., 2004; Lavoie et al., 2004), or with NTPDase8 from rat and human species. The other NTPDases which are more different in structures and in amino acid sequence identity (lower than $25 \%$ identity to mouse NTPDase8) were not tested. All the difficulties that we encountered to produce antibodies to mouse NTPDase8, especially those using synthetized peptides, suggests that this protein is poorly immunogenic.

In addition, the antibody against mouse NTPDase8 allowed the localization of NTPDase8 in mouse liver canaliculi as we previously observed for rat NTPDase8 (Fausther et al., 2007).

To generate monoclonal antibodies against human NTPDase8, an injection of human NTPDase8 transfected HEK 293T cells at the last boost after several cDNA immunizations was determined to be an efficient technique. The monoclonal antibodies against human NTPDase8 were also validated with different techniques. Our results show that these monoclonal antibodies are efficient in all techniques tested: Western blot (reduced and non-reduced conditions), indirect ELISA, immunohistochemistry (data not shown) and flow cytometry (Table 1). The four hybridomas may originate from the same original $\mathrm{B}$ cell clone since all experiments performed yielded similar results with each of the four monoclonal antibodies and that all are IgG2a.

In addition, we also tested commercial antibodies to mouse and human NTPDase8. Neither of them detected a specific band on Western blot under the conditions used in our experiments. Indeed, the same background bands could be seen in both COS7 extracts from cells overexpressing NTPDase8 and in COS-7 extract controls (Figures 1E, 3C). The commercial antibodies were used at the concentration recommended by the companies. It is noteworthy that we allowed an overreaction to detect any minor bands. As a comparative control which is illustrated in Figure 3C, the amount of cell lysates loaded, containing human NTPDase8, and time of reaction resulted in an intense band with the hN8-C5 $5_{s}$ antibody. Similar results were obtained when comparing the reaction obtained with $\mathrm{mN} 8-4_{c} \mathrm{I}_{5}$ antisera with the antibody from Santa Cruz (Figure 1E and data not shown).

\section{CONCLUSION}

In this work, we generated specific antibodies to mouse and human NTPDase8 with very convenient cDNA immunization techniques. These antibodies are useful for Western blot, ELISA, immunohistochemistry, immunocytochemistry, and flow cytometry. These antibodies allowed the immunolocalization of NTPDase8 in mouse liver canaliculi. It is noteworthy that the commercial antibodies tested here against mouse or human NTPDase8 failed to give a specific reaction. This reiterates previously published results evaluating other commercially available antibodies, which indicate that commercial antibodies need to be carefully validated before they can be correctly and 
effectively used, e.g., for antibodies against angiotensin II $\mathrm{AT}_{2}$ (Hafko et al., 2013), P2Y6 (Yu and Hill, 2013), and alpha1adrenergic receptor subtypes (Jensen et al., 2009).

\section{AUTHOR CONTRIBUTIONS}

JP performed Western blot, immunocytochemistry, activity tests, flow cytometry, and wrote the first draft of the manuscript; MS did immunohistochemistry assays; JL prepared the protein extracts; MF performed immunohistochemistry, immunocytochemistry, and Western blot; FB performed immunohistochemistry and immunocytochemistry; JS supervised the study.

\section{REFERENCES}

Bartel, D. L., Sullivan, S. L., Lavoie, E. G., Sévigny, J., and Finger, T. E. (2006). Nucleoside triphosphate diphosphohydrolase-2 is the ecto-ATPase of type I cells in taste buds. J. Comp. Neurol. 497, 1-12. doi: 10.1002/cne.20954

Baykov, A. A., Evtushenko, O. A., and Avaeva, S. M. (1988). A malachite green procedure for orthophosphate determination and its use in alkaline phosphatase-based enzyme immunoassay. Anal. Biochem. 171, 266-270. doi: 10.1016/0003-2697(88)90484-8

Beaudoin, A. R., Sévigny, J., and Picher, M. (1996). "ATP-diphosphohydrolases, apyrases, and nucleotide phosphohydrolases: biochemical properties and functions," in ATPases, ed. A. G. Lee (Greenwich: JAI Press Inc), 369-401. doi: 10.1016/s1874-5342(06)80015-2

Belcher, S. M., Zsarnovszky, A., Crawford, A. R., Hemani, H., Spurling, L., and Kirley, T. L. (2005). Immunolocalization of ectonucleoside triphosphate diphosphohydrolase 3 in rat brain: implication for modulation of multiple homeostatic systems including feeding and sleep-wake behaviors. Neuroscience 137, 1331-1346. doi: 10.1016/j.neuroscience.2005.08.086

Bigonnesse, F., Lévesque, S. A., Kukulski, F., Lecka, J., Robson, S. C., Fernandes, M. J. G., et al. (2004). Cloning and characterization of mouse nucleoside triphosphate diphosphohydrolase-8. Biochemistry 43, 5511-5519. doi: 10.1021/ bi0362222

Enjyoji, K., Sévigny, J., Lin, Y., Frenette, P. S., Christie, P. D., Schulte Am Esch Ii, J., et al. (1999). Targeted disruption of CD39/ATP diphosphohydrolase results in disordered hemostasis and thromboregulation. Nat. Med. 5, 1010-1017. doi: $10.1038 / 12447$

Fausther, M., Lecka, J., Kukulski, F., Lévesque, S. A., Pelletier, J., Zimmermann, H., et al. (2007). Cloning, purification and identification of the liver canalicular ecto-ATPase as NTPDase8. Am. J. Physiol. Gastrointest. Liver Physiol. 292, G785-G795.

Fausther, M., Lecka, J., Soliman, E., Kauffenstein, G., Pelletier, J., Sheung, N., et al. (2012). Coexpression of ecto-5'-nucleotidase/CD73 with specific NTPDases differentially regulates adenosine formation in the rat liver. Am. J. Physiol. Gastrointest. Liver Physiol. 302, G447-G459. doi: 10.1152/ajpgi. 00165.2011

Hafko, R., Villapol, S., Nostramo, R., Symes, A., Sabban, E. L., Inagami, T., et al. (2013). Commercially available angiotensin II At(2) receptor antibodies are nonspecific. PLoS ONE 8:e69234. doi: 10.1371/journal.pone.0069234

Jensen, B. C., Swigart, P. M., and Simpson, P. C. (2009). Ten commercial antibodies for alpha-1-adrenergic receptor subtypes are nonspecific. Naunyn Schmiedebergs Arch. Pharmacol. 379, 409-412. doi: 10.1007/s00210-0080368-6

Kaczmarek, E., Koziak, K., Sévigny, J., Siegel, J. B., Anrather, J., Beaudoin, A. R., et al. (1996). Identification and characterization of CD39 vascular ATP diphosphohydrolase. J. Biol. Chem. 271, 33116-33122. doi: 10.1074/jbc.271.51. 33116

Knowles, A. F., and Chiang, W. C. (2003). Enzymatic and transcriptional regulation of human ecto-ATPase/E-NTPDase 2. Arch. Biochem. Biophys. 418, 217-227. doi: 10.1016/j.abb.2003.08.007

\section{FUNDING}

This work was supported by a grant to J. Sévigny from the Canadian Institutes of Health Research (CIHR; MOP-102472). MS was a recipient of a scholarship from the Fonds de recherche du Québec-Santé (FRQS), MF of a doctoral Scholarship from the Government of Gabon and JS of a "Chercheur National" Scholarship award from the FRQS.

\section{DISCLAIMER}

The monies received to obtain the antibodies were reinvested into antibody generation and research.

Kukulski, F., Lévesque, S. A., Lavoie, E. G., Lecka, J., Bigonnesse, F., Knowles, A. F., et al. (2005). Comparative hydrolysis of P2 receptor agonists by NTPDases 1, 2, 3 and 8. Purinergic Signal. 1, 193-204. doi: 10.1007/s11302-005-6217-x

Kukulski, F., Lévesque, S. A., and Sévigny, J. (2011). Impact of ectoenzymes on P2 and P1 receptor signaling. Adv. Pharmacol. 61, 263-299. doi: 10.1016/B978-012-385526-8.00009-6

Lavoie, É. G., Kukulski, F., Lévesque, S. A., Lecka, J., and Sévigny, J. (2004). Cloning and characterization of mouse nucleoside triphosphate diphosphohydrolase-3. Biochem. Pharmacol. 67, 1917-1926. doi: 10.1016/j.bcp.2004.02.012

Martín-Satué, M., Lavoie, E. G., Pelletier, J., Fausther, M., Csizmadia, E., Guckelberger, O., et al. (2009). Localization of plasma membrane bound NTPDases in the murine reproductive tract. Histochem. Cell Biol. 131, 615-628. doi: 10.1007/s00418-008-0551-3

Munkonda, M. N., Pelletier, J., Ivanenkov, V. V., Fausther, M., Tremblay, A., Kunzli, B., et al. (2009). Characterization of a monoclonal antibody as the first specific inhibitor of human NTP diphosphohydrolase-3: partial characterization of the inhibitory epitope and potential applications. FEBS J. 276, 479-496. doi: 10.1111/j.1742-4658.2008.06797.x

Robson, S. C., Sévigny, J., and Zimmermann, H. (2006). The E-NTPDase family of ectonucleotidases: structure function relationships and pathophysiological significance. Purinergic Signal. 2, 409-430. doi: 10.1007/s11302-0069003-5

Sévigny, J., Robson, S. C., Waelkens, E., Csizmadia, E., Smith, R. N., and Lemmens, R. (2000). Identification and characterization of a novel hepatic canalicular ATP diphosphohydrolase. J. Biol. Chem. 275, 5640-5647. doi: 10. 1074/jbc.275.8.5640

Sévigny, J., Sundberg, C., Braun, N., Guckelberger, O., Csizmadia, E., Qawi, I., et al. (2002). Differential catalytic properties and vascular topography of murine nucleoside triphosphate diphosphohydrolase 1 (NTPDase1) and NTPDase2 have implications for thromboregulation. Blood 99, 2801-2809. doi: 10.1182/ blood.V99.8.2801

Smith, T. M., and Kirley, T. L. (1998). Cloning, sequencing, and expression of a human brain ecto-apyrase related to both the ecto-ATPases and CD39 ectoapyrases. Biochim. Biophys. Acta 1386, 65-78. doi: 10.1016/S0167-4838(98) 00063-6

Vandenbeuch, A., Anderson, C. B., Parnes, J., Enjyoji, K., Robson, S. C., Finger, T. E., et al. (2013). Role of the ectonucleotidase NTPDase 2 in taste bud function. Proc. Natl. Acad. Sci. U.S.A. 110, 14789-14794. doi: 10.1073/pnas.130946 8110

Vekaria, R. M., Shirley, D. G., Sévigny, J., and Unwin, R. J. (2006). Immunolocalization of ectonucleotidases along the rat nephron. Am. J. Physiol. Renal Physiol. 290, F550-F560. doi: 10.1152/ajprenal.00151.2005

Yegutkin, G. G. (2014). Enzymes involved in metabolism of extracellular nucleotides and nucleosides: functional implications and measurement of activities. Crit. Rev. Biochem. Mol. Biol. 49, 473-497. doi: 10.3109/10409238. 2014.953627

Yu, W., and Hill, W. G. (2013). Lack of specificity shown by P2Y6 receptor antibodies. Naunyn Schmiedebergs Arch. Pharmacol. 386, 885-891. doi: 10. 1007/s00210-013-0894-8 
Zimmermann, H., Zebisch, M., and Strater, N. (2012). Cellular function and molecular structure of ecto-nucleotidases. Purinergic Signal. 8, 437-502. doi: $10.1007 /$ s11302-012-9309-4

Conflict of Interest Statement: The authors declare that the research was conducted in the absence of any commercial or financial relationships that could be construed as a potential conflict of interest.
Copyright (๑) 2017 Pelletier, Salem, Lecka, Fausther, Bigonnesse and Sévigny. This is an open-access article distributed under the terms of the Creative Commons Attribution License (CC BY). The use, distribution or reproduction in other forums is permitted, provided the original author(s) or licensor are credited and that the original publication in this journal is cited, in accordance with accepted academic practice. No use, distribution or reproduction is permitted which does not comply with these terms. 